\title{
Fiber Bragg Grating (FBG) Sensors Used in Coal Mines
}

\author{
Jinyu WANG ${ }^{1 *}$, Tongyu LIU ${ }^{1,2}$, Guangdong $\mathrm{SONG}^{1}$, Hongjing $\mathrm{XIE}^{3}$, \\ Lianqing $\mathrm{LI}^{2}$, Xiaolin $\mathrm{DENG}^{4}$, and Zhijie $\mathrm{GONG}^{4}$ \\ ${ }^{1}$ Key Laboratory of Optical Fiber Sensing Technology of Shandong Province, Laser Institute, Shandong Academy of \\ Science, Jinan, 250014, China \\ ${ }^{2}$ Shandong Micro-Sensor Photonics Ltd., Jinan, 250014, China \\ ${ }^{3}$ Heat Energy and Electric Power Designing Institute of Shandong Province, Jinan, 250013, China \\ ${ }^{4}$ Yanzhou Coal Industry Company, Yanzhou, 272102, China \\ *Corresponding author: Jinyu WANGＥ-mail: wangjinyu105@163.com
}

\begin{abstract}
The fiber Bragg grating (FBG) strain sensors were used for on-line monitoring of the stress variation of the lined wall in the gateway retained along the goaf of No. 3203 coal mining face in Dongtan Mine. The results showed that the FBG strain sensor with the wide measuring range could measure the stress variation accurately during the support process of the gateway retained along the goaf and could provide the basis to further optimize the support structure and to determine the support plan of the gateway retained along the goaf. The FBG micro-seismic sensors were used in Xinglong Mine to detect the micro-seismic signal. The signals were well received and analyzed to determine the location and energy level of the source of the micro-seismic event warning. The FBG sensors and detecting system show a significant potential for micro-seismic detection and geological disasters detection.
\end{abstract}

Keywords: FBG, stress sensor, acceleration sensor, stress monitoring, micro-seismic activity, seismic signal

Citation: Jinyu WANG, Tongyu LIU, Guangdong SONG, Hongjing XIE, Lianqing LI, Xiaolin DENG, et al., "Fiber Bragg Grating (FBG) Sensors Used in Coal Mines," Photonic Sensors, 2014, 4(2): 120-124.

\section{Introduction}

With an increase in the production capacity, the underground mining becomes deeper and deeper, the earth stress increases too, and the influence of the rock movement caused by mining on the production and life is becoming more and more serious. The dynamic disasters in the coal mine such as roof fall, rock burst, and coal and gas outburst have occurred from time to time [1-3]. In order to ensure the safety of the coal mine production, rock displacement monitoring and early warning are needed imminently.
In order to ensure the sustainable development of the coal mine and prolong the service lifetime of the mine, the gateway retained along the goaf has become an important application technology [4]. Then, the backstoping tunnel, concentrated tunnel of the plate area and large section open-off cut can be retained by the gob-side entry retaining method. At present, the main problem existing in the gob-side entry retaining technology in our country is that the support design is not reasonable. The roadway support belongs to the passive support and has the problem in mechanical properties without adapting to the surrounding rock deformation of gob-side

Received: 14 December 2013 / Revised version: 18 February 2014

(C) The Authors(s) 2014. This article is published with open access at Springerlink.com

DOI: $10.1007 / \mathrm{s} 13320-014-0160-9$

Article type: Regular 
entry retaining, the control mechanism on the gob-side roadway surrounding rock is not enough in-depth study and so on. The monitoring on the support effect of gob-side entry retaining is a necessary means to test support method's rationality.

The fiber Bragg gratings have many advantages such as the low power transmission, immunity to electromagnetic interference, intrinsic safety, stable chemical property, long transmission distance, and convenience for multiplexing, and they are particularly suitable for the flammable, explosive, and strong electromagnetic environments. The on-line process monitoring of the working face and roadway supporting is very necessary using the fiber Bragg grating micro-seismic sensor and stress sensor with a large range.

In this paper, the FBG strain sensors installed on the concrete wall and the FBG micro-seismic sensors are analyzed. The pressure curve got by the FBG strain sensors reflects the changes in the strain of the concrete wall. A group of micro-seismic data are illustrated in the aspect of energy, length of time of the signal, and frequency. The results show the FBG sensors can be used in coal mines for coal mines safety.

\section{FBG stress sensor applied in the coal mine}

It is known that the reflective wavelength of the Bragg grating changes with the change in the strain or temperature of the environment [5]. The relation between the strain and wavelength shift of the Bragg grating can be expressed as

$$
\frac{\Delta \lambda_{b}}{\lambda_{b}}=0.78 \varepsilon
$$

where $\lambda_{b}$ is the Bragg wavelength; $\Delta \lambda_{b}$ is Bragg wavelength-shift; $\varepsilon$ is the strain.

The fiber Bragg grating is packaged using a metallic elastic cylinder as the substrate. Based on the generalized Hooke's law and (1), $\Delta \lambda_{b}$ can be written as follows:

$$
\Delta \lambda_{B}=\frac{0.39 d \lambda_{B}}{E h} \cdot\left(1-\frac{1}{2} \cdot \mu\right) \cdot P
$$

where $d$ is the inside diameter of the barrel; $E$ is the elastic modulus of the barrel material; $h$ is the thickness of the wall; $\mu$ is the material Poisson ratio of the strain barrel; $P$ is the pressure. According to (2), the drift of the central wavelength of the FBG and the measured pressure show a linear relationship.

The measuring range of the pressure changes with the change in the thickness of the wall and the inside diameter of the barrel. Figure 1 shows the packaged FBG strain sensor. The front end of the sensor is connected to an oil pocket. When the oil pocket is pressed, the pressure is delivered to the sensor cavity by the hydraulic oil chamber, so the reflective wavelength of the FBG changes subsequently. The FBG strain sensor was demodulated by BaySpec.

The FBG strain sensor was calibrated by a GE sensing baresthesiometer (Model P3125-1). Figure2 shows that the FBG strain sensor has the better linearity, and the sensitivity coefficient of the stress sensor is $0.0234 \mathrm{~nm} / \mathrm{MPa}$.

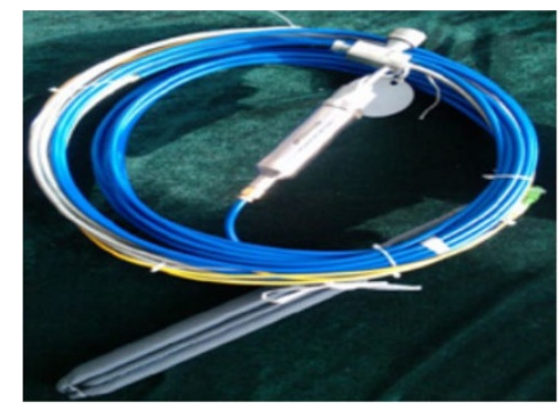

Fig. 1 Packaged FBG strain sensor.

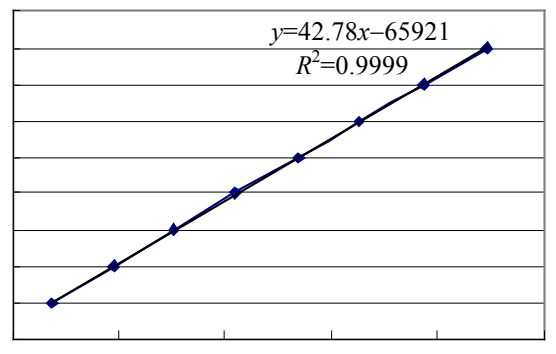

Fig. 2 Calibration of the FBG strain sensor. 
The FBG stress sensors were installed in Dongtan Mine. When stopping mining, the sensors were installed in the wake of building the lined wall in the gateway retained along the goaf of No. 3203 coal mining face. There were 20 sensors that were separated from each other for $10 \mathrm{~m}$. All sensors were fixed in the basal position of the lined wall in the gateway retained along the goaf.

Figure 3 exhibits the detecting data of the FBG press sensor. These data show the pressure changes of the concrete wall. These sensors were installed identically. Figure 3 shows the pressure data increased along with the sinking roof caused by mining. Three days later, the pressure data reached to the peak. At this moment, the working surface moved forward about $15 \mathrm{~m}$ continuously. The upper strata in the gateway retained along the goaf had the greatest activity; the tunnel roof went down rapidly, and the floor was heaved violently, so the concrete wall pressure reached the maximum value. Subsequently with the roof caving, the goaf was filled with the waste rock, so the concrete wall and waste rock supported the upper strata together, then the pressure data decreased. With the compactness of the waste rock, the supporting point fell down, the pressure on the concrete wall increased a little, so the pressure curve went up. Ten days later, the working surface moved forward about $50 \mathrm{~m}$ continuously, the activities of the surrounding rock tended to be stable finally, and the pressure curve had no changes.

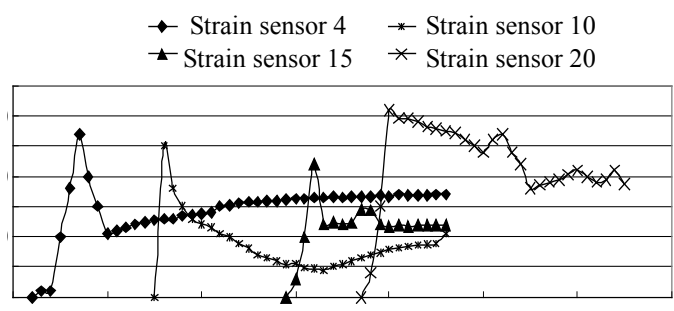

Fig. 3 On-site monitoring data curve of the FBG pressure sensor.

It can be seen from Figure3, the pressure data monitored by four sensors have basically the same trend. These data reflect the changes in the wall pressure during the mining period. But because of the different actual pressures of different positions, the test curves are not exactly the same.

\section{FBG acceleration sensor applied in the coal mine}

The FBG acceleration sensors were designed using a cantilever beam $[6,7]$. The sensitivity of the FBG acceleration sensor was $420 \mathrm{pm} / \mathrm{g}$, and the resonance oscillation frequency was $120 \mathrm{~Hz}$. The FBG acceleration sensor was demodulated by a tunable distributed feedback (DFB) laser [6, 7].

A field test system was established in the coal mine in Xinglong village, Shandong Province. Eighteen fiber micro-seismic sensors were installed in the coal mine. Figure 4 exhibits the setting locations of the four sensors among the eighteen sensors in the form of the red ball. The longest distance was about five kilometers. The shortest distance was three kilometers.

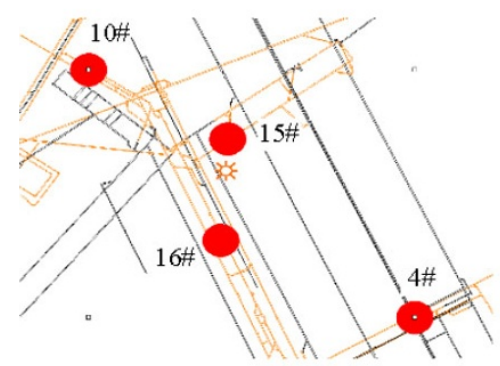

Fig. 4 Setting locations of the four FBG geophones.

Figure 5 shows the FBG geophone horizontally settled in the coal mine. These FBG geophones were put into the coal-bed about 5-m depth horizontally, and the cement was poured into the installation hole to enable the sensor and coal mine integration. But this method has one drawback that it cannot pour the cement fully. Figure 6 shows the improved FBG geophone so that the geophone can be coupled well with the coals. Figure 7 exhibits the micro-seismic demodulator and data processor. Figure 8 presents the micro-seismic signals obtained by the FBG geophone system at twenty-six past seventeen on May 7. 2013. In Fig. 4, the channels captured the 
evident seismic signals in the same time frame with different arrival moments which corresponded to the different distances to the seismic source. Sensor 15 received the signal at first, and Sensor 4 received at last. Figure 4 also shows the positioning results in the form of sun. Tables 1 and 2 exhibit the length of time, frequency range, basic frequency, amplitude, and signal to noise ratio (SNR) of the seismic signals of different sensors.

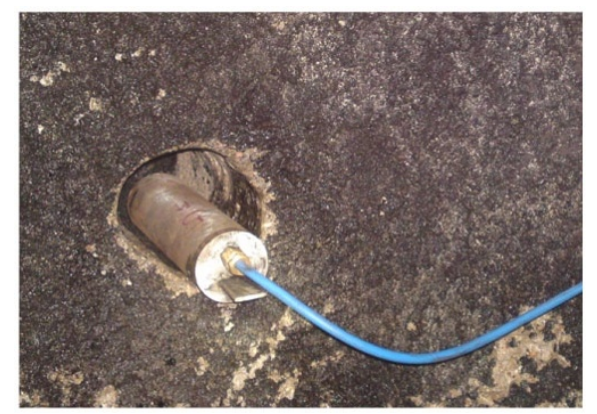

Fig. 5 FBG geophone installed horizontally.

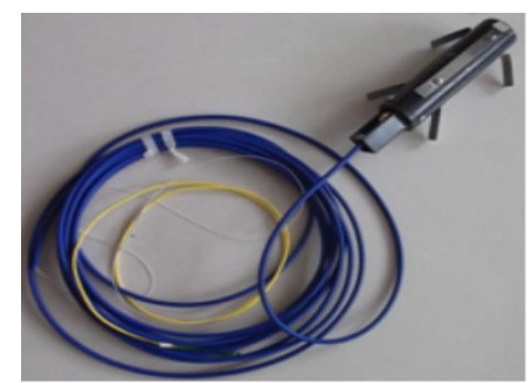

Fig. 6 Improved FBG geophone.

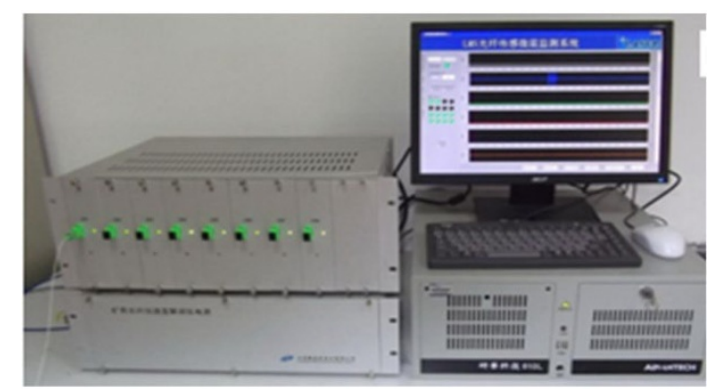

Fig. 7 Micro-seismic demodulator and data processor.

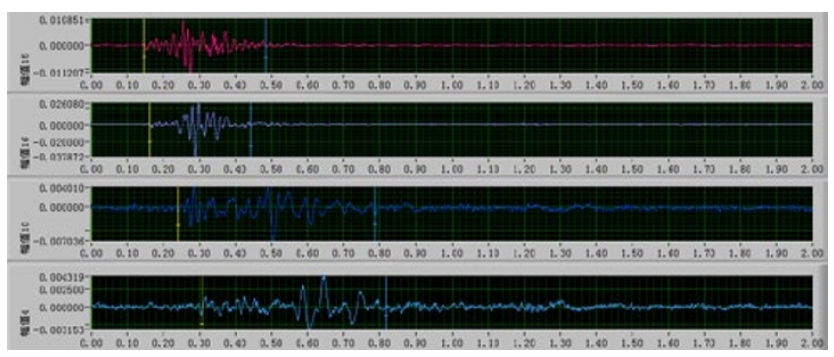

Fig. 8 Micro-seismic signals got by the FBG system.
Table 1 Length of time and frequency range versus basic frequency.

\begin{tabular}{c|c|c|c}
\hline $\begin{array}{c}\text { Sensor } \\
\text { ID }\end{array}$ & $\begin{array}{c}\text { Length of time } \\
(\mathrm{S})\end{array}$ & $\begin{array}{c}\text { Frequency range } \\
(\mathrm{Hz})\end{array}$ & $\begin{array}{c}\text { Basic frequency } \\
(\mathrm{Hz})\end{array}$ \\
\hline $15 \#$ & 0.34 & $4-90$ & 56.5 \\
\hline $16 \#$ & 0.28 & $5-80$ & 50 \\
\hline $10 \#$ & 0.55 & $4-40$ & 20 \\
\hline $4 \#$ & 0.51 & $4-40$ & 8 \\
\hline
\end{tabular}

Table 2 Amplitude versus SNR.

\begin{tabular}{c|c|c}
\hline Sensor ID & Amplitude $\left(\mathrm{m} / \mathrm{s}^{2}\right)$ & SNR $(\mathrm{dB})$ \\
\hline $15 \#$ & 0.01 & 36.52 \\
\hline $16 \#$ & 0.026 & 31.07 \\
\hline $10 \#$ & 0.004 & 20.67 \\
\hline $4 \#$ & 0.0043 & 24.66 \\
\hline
\end{tabular}

It can be seen from the tables above, the length of time of the micro-seismic signal was between $0.28 \mathrm{~s}$ and $0.55 \mathrm{~s}$, the basic frequency changed between $8 \mathrm{~Hz}$ and $56.5 \mathrm{~Hz}$, the frequency attenuated, and the SNR decreased along with an increase in the distance. As shown in Figure 4, the earthquake source was nearest to Sensor 15 in the plan. The $Z$ coordinates of Sensor 15, Sensor 16, Sensor 10, and Sensor 4 were $-363 \mathrm{~m},-411 \mathrm{~m},-348 \mathrm{~m},-446 \mathrm{~m}$, and the $Z$ coordinate of the source geodetic was $-518 \mathrm{~m}$, so Sensors 16 and 4 were nearer to the source rather than Sensors 15 and 10 in the vertical direction. The shock waves in the vertical propagation process should wear the earth layer. This propagation mode lost the larger energy than that in the same layer transmission, so the amplitude of Sensor 16 was larger than that of Sensor 15, and the amplitude of Sensor 4 was larger than that of Sensor 10.

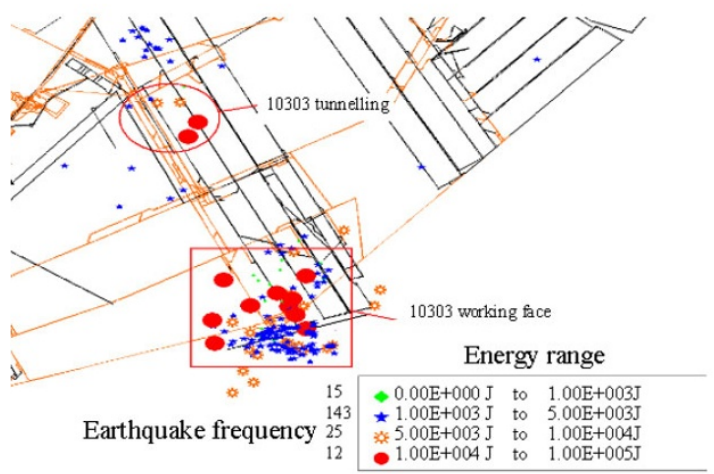

Fig. 9 FBG geophone horizontally installed.

Figure 9 shows the distribution plan of the micro-seismic events during April 1 to May 13, 
2013. It can be seen that the micro-seismic events were mainly distributed in the No. 10303 working face during backstopping. The distribution of the mine earthquake has obvious regional characteristics and is closely related to the mining activities.

\section{Conclusions}

This paper introduces the FBG strain sensor and acceleration sensor applied in coal mines. The results showed that the FBG strain sensor with a high measuring range could measure the stress changes accurately during the support process of the gateway retained along the goaf and could provide the basis to further optimize the support structure and to determine the support plan of the gateway retained along the goaf. The data got from FBG acceleration sensors illustrated micro-seismic events were a series of signals whose basic frequencies were mainly less than $50 \mathrm{~Hz}$. Detecting micro-seismic signals on line over a long period of time can forecast geological disasters.

\section{Acknowledgment}

This work was partly supported by the Shandong Major Special Program of the Independent Innovation Achievement Transformation (No. 2011ZHZX1A0107).
Open Access This article is distributed under the terms of the Creative Commons Attribution License which permits any use, distribution, and reproduction in any medium, provided the original author(s) and source are credited.

\section{References}

[1] L. Dou, C. Zhao, S. Yang, Prevention of rock burst in coal mining. Xuzhou: China University of Ming and Technology Press, 2006.

[2] L. Dou and X. He. Theory and technology in the prevention of rock burst. Xuzhou: China University of Ming and Technology Press, 2001.

[3] J. Yao and L. Dou, "Rock burst mechanism and measurement of controlling rock burst in burst in coal mining roadway," in Progress in Safety Science and Technology, Shanghai, Oct. 25-28, 2004.

[4] J. P. Wilkinson, "Nonlinear resonant circuit devices," U.S. Patent 3624 12, Jul. 16, 1990.

[5] A. W. Domanski and P. Lesiak, "Comparision of Bragg and polarimetric optical fiber sensors for stress monitoring in composite materials," Acta Physica Polonica A, 2009, 116(3): $294-296$.

[6] J. Wang, D. Huo, J. Chang, X. Liu, T. Liu, and C. Wang, "A temperature self-adapting FBG vibrating sensor system," in Proc. SPIE, vol. 7503, pp. 750343 , 2009.

[7] J. Wang, T. Liu, C. Wang, X. Liu, D. Huo, and J. Chang, "A micro-seismic fiber Bragg grating (FBG) sensor system based on distributed feedback laser," Measurement Science and Technology, 2010, 21(9): 094012. 